\title{
The Long-term Effect of Superficial Bladder Neck Incision on Ejaculation and Incontinence in Boys with Primary and Secondary Bladder Neck Obstruction
}

Pauline M. L. Hennus ${ }^{1 *}$, Esther Hoenjet ${ }^{1}$, Jan H. Kieft ${ }^{1}$, Tom P. V. M. de Jong ${ }^{2}$ and Laetitia M. O. de Kort ${ }^{1}$

${ }^{1}$ Department of Urology, University Medical Center Utrecht, Utrecht, Netherlands, ${ }^{2}$ Department of Pediatric Urology, University Children's Hospitals UMC Utrecht and AMC Amsterdam, Utrecht, Netherlands

Objective: Superficial bladder neck incision (SBNI) is controversial at young age, with retrograde ejaculation after puberty as main concern. The aim of the study is to investigate the long-term effect of SBNI on ejaculation and incontinence in boys with primary and secondary bladder neck obstruction (BNO).

\section{OPEN ACCESS}

Edited by:

Ubirajara Barroso Jr.,

Federal University of Bahia, Brazil

Reviewed by:

José Murillo B. Netto,

Universidade Federal de

Juiz de Fora, Brazil

Pedro-José Lopez,

Hospital Exequiel Gonzalez

Cortes \& Clinica Alemana, Chile

*Correspondence:

Pauline M. L. Hennus paulinehennus@gmail.com

Specialty section:

This article was submitted

to Pediatric Urology,

a section of the journal

Frontiers in Pediatrics

Received: 06 January 2017 Accepted: 19 June 2017 Published: 13 July 2017

Citation:

Hennus PML, Hoenjet E, Kieft JH, de Jong TPVM and de Kort LMO

(2017) The Long-term Effect of Superficial Bladder Neck Incision on Ejaculation and Incontinence in Boys with Primary and Secondary Bladder Neck Obstruction.

Front. Pediatr. 5:152. doi: 10.3389/fped.2017.00152
Materials and methods: In boys with infravesical obstruction, SBNI was performed in case of a persistent BNO after earlier desobstruction or in case of primary severely obstructive bladder neck. SBNI was performed with a diathermy hook, always superficially $(2-3 \mathrm{~mm})$ and unilaterally at 7 O'clock. Males that had SBNI during childhood after posterior urethral valve incision or relief of other obstruction between 1986 and 2003 were included. Evaluation was done by International Continence Society male sex questionnaire, International Prostate Symptom Score, developmental International Consultation Modular Questionnaire on Urinary Incontinence, frequency volume chart, and uroflowmetry.

Results: Of 79 traceable patients, 40 (50.6\%) participated. Of these, 37 (92.5\%) completed all questionnaires and $28(70 \%)$ performed uroflowmetry. Median age at SBNI was 4.7 years [interquartile range (IQR) 0.6-8.5] and was 19.6 years (IQR 17.3-20.9) at follow-up. All men had antegrade ejaculation, 4/37 (10.8\%) reported possibly reduced ejaculatory volume. Eight (22\%) had moderate lower urinary tract symptoms and two (5.4\%) had moderate incontinence. Median maximum flow rate was $30.1 \mathrm{~mL} / \mathrm{s}$ (IQR 24.4-42.6).

Conclusion: SBNI in boys with severe infravesical obstruction can be done safely with preservation of antegrade ejaculation and no additional lower urinary tract dysfunction.

Keywords: bladder neck incision, bladder neck obstruction, boys, long-term follow-up, posterior urethral valves, retrograde ejaculation

\footnotetext{
Abbreviations: SBNI, superficial bladder neck incision; BNO, bladder neck obstruction; ED, endoscopic desobstruction; FVC, frequency volume chart; ICIQ-UI, International Consultation on Incontinence Modular Questionnaire-Urinary Incontinence; ICS male sex, International Continence Society male sex; IPSS, International Prostate Symptom Score; IQR, interquartile range; LUTS, lower urinary tract symptoms; PUV, posterior urethral valve; PUVI, posterior urethral valve incision; PVR, post-void residual; QoL, quality of life; $\mathrm{Q}_{\max }$, maximum flow rate; UI, urinary incontinence; UTIs, urinary tract infections; VUR, vesicoureteral reflux.
} 


\section{INTRODUCTION}

Bladder neck obstruction (BNO) is a condition described as an insufficient opening of the bladder neck during voiding due to a functional or anatomic narrowing of the bladder neck and was first described by Marion in 1933 (1). The underlying cause of primary BNO remains unclear. In boys with posterior urethral valves (PUV), BNO is often present and caused by detrusor hypertrophy with subsequent narrowing of the bladder neck $(2,3)$. In most cases of PUV, BNO disappears spontaneously over time after PUV incision due to disappearance of detrusor hypertrophy. Persistent BNO after PUV or other obstruction incision may contribute to lower urinary tract symptoms (LUTS), urinary incontinence (UI), urinary tract infections (UTIs), and vesicoureteral reflux (3-6). Untreated persistent bladder outlet obstruction may lead to progressive symptoms, as well as upper and lower urinary tract decompensation $(2,7)$.

In the past, persistent $\mathrm{BNO}$ in children has been treated by $\mathrm{Y}-\mathrm{V}$ bladder neck plasty. Others treated BNO by temporary vesicostomies or by alpha blocking pharmaceuticals. Many believe that bladder neck hypertrophy and narrowing is just the consequence of a more distal obstruction and does not act as an obstruction itself. After PUV incision (PUVI), the appearance and function of the bladder neck usually improves (3). In 1973 Turner-Warwick et al. introduced a bladder neck incision (BNI) technique in adults (8). After bilateral BNI in adult men, retrograde ejaculation occurs in $21 \%$ (9). Also, unilateral BNI in adults reduced sperm count to $70 \%$, while a limited unilateral BNI seemed to preserve antegrade ejaculation in most men $(10,11)$. In order to avoid complications, when needed, we perform a unilateral superficial bladder neck incision (SBNI) only at 7 O'clock. It is unknown whether complications after BNI in adults, such as retrograde ejaculation, reduced sperm count, and bladder neck stricture, will also appear after SBNI in early childhood. In particular, retrograde ejaculation is a concern for these boys who might want to become fathers in the future. For this reason, SBNI in boys and young men remains controversial.

The goals of this study were to investigate the presence of antegrade ejaculation on the long term after unilateral SBNI performed during childhood and to evaluate long-term voiding symptoms. Primary investigation tools were questionnaires concerning sexual function and voiding problems.

\section{MATERIALS AND METHODS}

\section{Study Population}

This observational cross-sectional cohort study was approved by the local ethical committee. Male patients who underwent transurethral treatment for infravesical obstruction at our institution between January 1985 and December 2003 were retrospectively retrieved through the hospital surgical registration database. Patients with neurogenic bladder or congenital anomaly of the penis (hypospadias or epispadias) were excluded. Contact details of patients were obtained. Patients were informed by telephone about the goal and design of the study and asked to complete written informed consent, questionnaires, and a frequency volume chart (FVC). Patients were invited to our outpatient clinic for uroflowmetry. Baseline characteristics were obtained by reviewing medical records.

Included patients were 18 years or older at time of study and did have SBNI at early age. Cystoscopy was performed based on complaints very suggestive for obstruction, obstructive flow, or urodynamic study proving obstruction. Primary SBNI was performed when the bladder neck was considered severely obstructive during cystoscopy. SBNI was performed with a diathermy hook, always superficially $(2-3 \mathrm{~mm})$ and unilaterally at 7 O'clock. The incision was done to interrupt the obstructive circle. In Figures 1-3 we show examples before and after treatment. Secondary SBNI was performed if BNO did not disappear after endoscopic desobstruction (ED) of PUV or any other obstructive structure. Persistent BNO was confirmed by urodynamic study (Pdet- $\mathrm{Q}_{\max }>50 \mathrm{cmH}_{2} \mathrm{O}$ ) or voiding cystography (constriction of the bladder neck). Patients have been followed subsequently until confirmation that LUTS had subsided. Patients with a history of PUV, upper urinary tract problems, and a valve bladder were kept under regular controls till after puberty.

\section{Study Parameter Questionnaires}

Questions 3 and 4 of the International Continence Society male sex questionnaire (ICS male sex) were used to evaluate the presence of antegrade ejaculation. The International Prostate Symptom Score (IPSS) and quality of life (IPSS-QoL) and questions 7-12 of the developmental version of the International Consultation on Incontinence Modular Questionnaire-Urinary Incontinence (ICIQ-UI) were also used (12-14).

The IPSS was divided in four categories: "no symptoms" (score 0 ), "mild symptoms" (score 1-7), "moderate symptoms" (score 8-19), and "severe symptoms" (score 20-35). Individual IPSS question scores were divided in three categories: "never" (score 0), "rarely" (score 1), and "regularly/often" (score 2-5).

Because it was unknown whether SBNI would lead to a specific form of incontinence, the developmental ICIQ-UI questionnaire was used and not the ICIQ-short form. The ICIQ-UI questionnaire

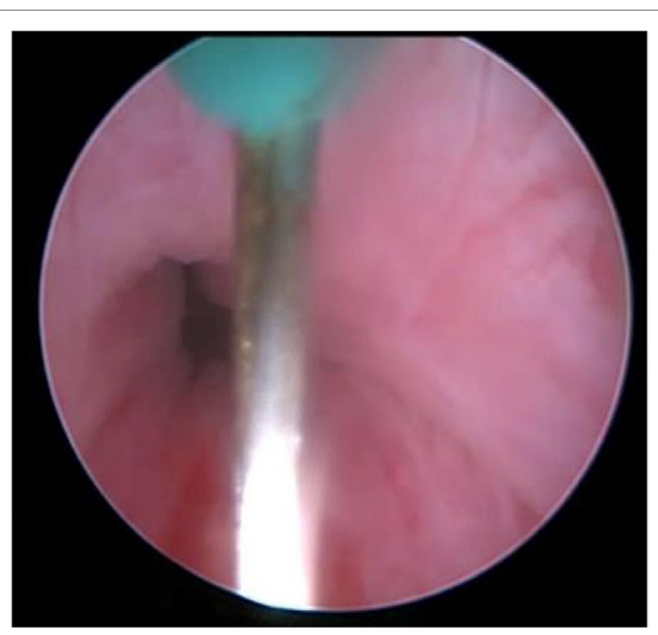

FIGURE 1 | Obstructive bladder neck, proven with urodynamic study. 


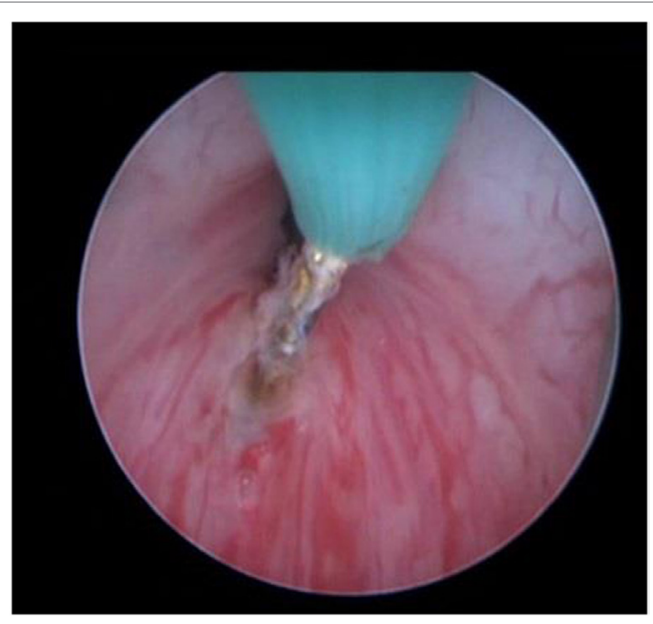

FIGURE 2 | Performing superficial bladder neck incision with hook diathermia.

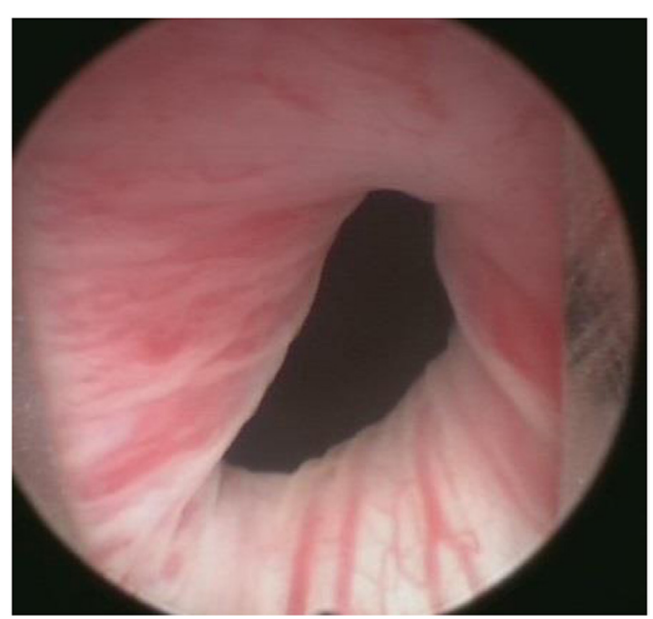

FIGURE 3 | 10 months after superficial bladder neck incision at 7 O'clock.

makes it possible to distinguish between stress, urge, nocturnal, and post-void incontinence, or incontinence for unknown reason. The ICIQ-UI score was divided in four categories: "no symptoms" (score 0), "mild symptoms" (score 1-6), "moderate symptoms" (score 7-15), and "severe symptoms" (score 16-24). Individual ICIQ-UI question scores were divided in three categories: "never" (score 0), "rarely" (score 1), and "regularly/often" (score 2-4). For the content of the questionnaires and additional questions, see the Tables 1-4 and Box 1.

\section{Measurements}

Uroflowmetry using an UroDyn ${ }^{\circledR} 1000$ was performed. Post-void residual (PVR) was measured using a BladderScan ${ }^{\circledR}$. Obtained parameters were voiding time, flow time, maximum flow rate $\left(\mathrm{Q}_{\max }\right)$, time to $\mathrm{Q}_{\max }$, average flow rate, voided volume, and flow pattern. Measurements with a voided volume $\leq 100 \mathrm{~mL}$, or not representative flow according to the patient, were excluded from analysis. The Pernkopf nomogram was used for interpretation to plot $\mathrm{Q}_{\max }$ versus voided volume (15). The ICS nomenclature was used to describe the flow curves. A PVR of $\geq 100 \mathrm{~mL}$ was defined as significant in these adult young men.

\section{Statistical Analysis}

Descriptive statistics were used. Data are presented as median with interquartile range (IQR), frequencies, and percentages. IPSS and ICIQ-UI scores were categorized. Data were analyzed using IBM-SPSS ${ }^{\circledR}$ version 20.0 for Windows with chi-square test and Mann-Whitney $U$ test.

\section{RESULTS}

\section{Study Population \\ General}

During the study period, 106 patients underwent SBNI; 79 were traceable, 42 patients returned questionnaires or performed uroflowmetry. Two of them did not sign informed consent for unknown reasons. Of the 40 included patients, 37 (92.5\%) fully completed the questionnaires and 30 (75\%) performed uroflowmetry. Two uroflowmetry measurements were excluded: one because of a voided volume $<100 \mathrm{~mL}$ and another because it was not representative.

\section{Baseline}

Table 1 presents the baseline characteristics for the entire group and also for the patients with PUV and patients without PUV. Median age at first ED was 2.7 years (IQR 0.2-7.8), and at the SBNI, the median age was 4.7 years (IQR 0.6-8.5). In 27 patients a primary BNI was performed. Median follow-up time since first ED was 19.6 years (IQR 17.3-20.9). Median age at follow-up was 22.5 years (IQR 20.8-26.2). Most patients underwent multiple interventions: 27 patients had PUVI, 19 internal urethrotomy for distal urethral stenosis, 11 urethral dilatation, and 10 incision of an utricular remnant. Thirteen patients had BNI combined with another desobstruction than PUV. Six patients were treated with SBNI alone. Age at first treatment was younger in the BNI and PUV group; 1.9 versus 4.9 years, $p=0.3$. Of patients with PUV, $63 \%$ needed re-intervention versus $15 \%$ in the group without PUV, $p<0.001$.

\section{Questionnaires}

Tables 2 and 3 present the results of the questionnaires for the whole group and for the patients with or without PUV.

\section{ICS Male Sex}

None of the patients experienced antegrade ejaculation. Four patients $(10.8 \%)$ had the impression of a reduced ejaculatory volume and three $(8.1 \%)$ had minor discomfort during ejaculation. We found no significant difference between patients treated with BNI and PUV and patients with BNI without treatment of PUV, $p=0.51$.

\section{International Prostate Symptom Score}

The median IPSS was 4 (IQR 1-6) and IPSS-QoL was 1 (IQR 0-1). IPSS correlated with QoL with a coefficient of $0.46(p=0.005)$. Of the 
TABLE 1 | Baseline characteristics.

\begin{tabular}{|c|c|c|c|c|c|}
\hline Total no. of patients & 40 & All & $27 \mathrm{BNI}$ and PUV & 13 BNI no PUV & $p$-Value \\
\hline Median age at first ED, years (IQR) & 2.7 & $(0.2-7.8)$ & $1.9(0.1-7.5)$ & $4.9(0.3-8.3)$ & 0.36 \\
\hline Median age at SBNI, years (IQR) & 4.7 & $(0.6-8.5)$ & $3.2(0.9-9.4)$ & $4.9(0.4-8.3)$ & 0.67 \\
\hline Median age at follow-up, years (IQR) & 22.5 & $(20.8-26.2)$ & $22.4(20.5-26.3)$ & $24.0(21.3-26.7)$ & 0.30 \\
\hline Median follow-up time, years (IQR) & 19.6 & $(17.3-20.9)$ & $19.6(18.8-20.7)$ & $19.6(16.9-21.1)$ & 0.92 \\
\hline Number of endoscopic procedures & & & & & 0.01 \\
\hline 1 time (\%) & 21 & $(52.5)$ & $10(37)$ & $11(85)$ & \\
\hline 2 times $(\%)$ & 11 & (27.5) & $10(37)$ & $1(7.5)$ & \\
\hline 3 times (\%) & 4 & $(10.0)$ & $4(15)$ & 0 & \\
\hline 4 times (\%) & 4 & $(10.0)$ & $3(11)$ & $1(7.5)$ & \\
\hline \multicolumn{6}{|l|}{ Endoscopic procedures } \\
\hline No. PUVI (\%) & 27 & $(67.5)$ & $27(100)$ & $0(0)$ & \\
\hline No. urethrotomia (\%) & 19 & $(47.5)$ & $13(48)$ & $6(46)$ & \\
\hline No. dilatation (\%) & 11 & $(27.5)$ & $9(33)$ & $2(15)$ & \\
\hline No. utricular remnant incision (\%) & 10 & $(25)$ & $8(30)$ & $2(15)$ & \\
\hline No. other ED, with incision (\%) & 2 & (5) & $1(3.7)$ & $1(7.5)$ & \\
\hline
\end{tabular}

SBNI, superficial bladder neck incision; BNI, bladder neck incision; ED, endoscopic desobstruction; PUV, posterior urethral valve; PUVI, PUV incision; IQR, interquartile range; No., number; VUR, vesicoureteral reflux.

TABLE 2 | Questionnaire results.

\begin{tabular}{|c|c|c|c|c|c|}
\hline Total patients in study (\%) & 40 & (100) & $\begin{array}{l}\text { BNI and } \\
\text { PUV }\end{array}$ & $\begin{array}{l}\text { BNI no } \\
\text { PUV }\end{array}$ & $p$-value \\
\hline No. of respondents (\%) & 37 & $(92.5)$ & & & \\
\hline \multicolumn{6}{|l|}{ ICS 3-ejaculation } \\
\hline No. normal ejaculation (\%) & 33 & $(89.2)$ & $22(92)$ & $11(85)$ & \\
\hline $\begin{array}{l}\text { No. ejaculation with reduced } \\
\text { amount (\%) }\end{array}$ & 4 & $(10.8)$ & $2(8)$ & $2(15)$ & \\
\hline $\begin{array}{l}\text { No. ejaculation not anymore/ } \\
\text { never had (\%) }\end{array}$ & 0 & (0) & $0(0)$ & $0(0)$ & \\
\hline \multicolumn{6}{|l|}{$\begin{array}{l}\text { ICS } 4-\text { pain or discomfort } \\
\text { during ejaculation }\end{array}$} \\
\hline No. no pain or discomfort (\%) & 34 & $(91.9)$ & $22(92)$ & $12(92)$ & \\
\hline No. minor pain or discomfort (\%) & 3 & $(8.1)$ & $2(2)$ & $1(8)$ & \\
\hline $\begin{array}{l}\text { No. moderate/severe pain or } \\
\text { discomfort (\%) }\end{array}$ & 0 & $(0)$ & $0(0)$ & $0(0)$ & \\
\hline \multicolumn{6}{|l|}{ IPSS } \\
\hline Median score (IQR) & 4 & $(1-6)$ & $2.5(1-6)$ & $5(3-10)$ & 0.03 \\
\hline Median bother score (IQR) & 0 & $(0-1.5)$ & $0(0-1)$ & $0(0-2)$ & 0.67 \\
\hline No. no LUTS (\%) & 5 & (13.5) & $5(21)$ & $0(0)$ & \\
\hline No. mild LUTS (\%) & 24 & $(64.9)$ & $15(62)$ & $9(69)$ & \\
\hline No. moderate LUTS (\%) & 8 & $(21.6)$ & $4(17)$ & $4(31)$ & \\
\hline No. severe LUTS (\%) & 0 & (0) & $0(0)$ & $0(0)$ & \\
\hline \multicolumn{6}{|l|}{ IPSS 8-quality of life } \\
\hline No. satisfied (\%) & 33 & $(89.2)$ & $21(59)$ & $12(92)$ & \\
\hline $\begin{array}{l}\text { No. equally satisfied/ } \\
\text { dissatisfied (\%) }\end{array}$ & 2 & $(5.4)$ & $2(29)$ & $0(0)$ & \\
\hline No. dissatisfied (\%) & 2 & $(5.4)$ & $1(8)$ & $1(8)$ & \\
\hline \multicolumn{6}{|l|}{ ICIQ-UI } \\
\hline Median score (IQR) & 1 & $(0-2.5)$ & $0(0-1)$ & $2(1-3.5)$ & 0.01 \\
\hline Median bother score (IQR) & 0 & $(0-1)$ & $0(0-0)$ & $0(0-1)$ & 0.17 \\
\hline No. no UI (\%) & 16 & $(43.2)$ & $14(58)$ & $2(15)$ & \\
\hline No. mild UI (\%) & 19 & $(51.4)$ & $8(34)$ & $11(85)$ & \\
\hline No. moderate UI (\%) & 2 & $(5.4)$ & $2(8)$ & $0(0)$ & \\
\hline No. severe UI & 0 & (0) & $0(0)$ & $0(0)$ & \\
\hline
\end{tabular}

ICIQ-UI, International Consultation on Incontinence Modular Questionnaire-Urinary Incontinence; ICS, International Continence Society; IPSS, International Prostate Symptom Score; LUTS, lower urinary tract symptoms; IQR, interquartile range; No., number; UI, urinary incontinence; PUV, posterior urethral valve; BNI, bladder neck incision.
TABLE 3 | Questionnaire results IPSS and ICIQ-UI.

\begin{tabular}{lcccc}
\hline IPSS & Never & $\begin{array}{c}<\mathbf{1 / 5} \text { of } \\
\text { time }\end{array}$ & $<\mathbf{1 / 2}$ of time & $\begin{array}{c}>\mathbf{1 / 2} \text { of } \\
\text { time }\end{array}$ \\
\cline { 2 - 5 } & $\mathbf{N ~ ( \% )}$ & $\mathbf{N ~ ( \% )}$ & $\mathbf{N ~ ( \% )}$ & $\mathbf{N}$ (\%) \\
\hline Incomplete emptying & $21(57)$ & $9(24)$ & $5(13)$ & $2(6)$ \\
Frequency & $11(30)$ & $16(43)$ & $7(19)$ & $3(8)$ \\
Intermittency & $24(65)$ & $9(24)$ & $3(8)$ & $1(3)$ \\
Urgency & $26(70)$ & $8(22)$ & $2(5)$ & $1(3)$ \\
Weak stream & $21(57)$ & $13(35)$ & $1(3)$ & $2(5)$ \\
Straining & $25(68)$ & $8(22)$ & $1(3)$ & $3(8)$ \\
Nocturia & $25(68)$ & $10(27)^{\star}$ & $1(3)^{\star \star}$ & $1(3)^{\star \star \star}$ \\
\hline ICIQ-UI & $\mathbf{N e v e r}$ & $\mathbf{R a r e l y}$ & $\mathbf{R e g u l a r l y}$ & $\mathbf{M o s t l y}$ \\
\hline Urgency & $24(65)$ & $9(24)$ & $4(11)$ & $0(0)$ \\
Urge incontinence & $31(84)$ & $4(11)$ & $2(5)$ & $0(0)$ \\
Stress incontinence & $37(100)$ & $0(0)$ & $0(0)$ & $0(0)$ \\
Incontinence eci & $33(89)$ & $3(8)$ & $1(3)$ & $0(0)$ \\
Nocturnal incontinence & $32(87)$ & $5(13)$ & $0(0)$ & $0(0)$ \\
Post-void dribbling & $22(60)$ & $11(30)$ & $3(8)$ & $0(0)$ \\
\hline
\end{tabular}

IPSS, International Prostate Symptom Score; ICIQ-UI, International Consultation on Incontinence Modular Questionnaire-Urinary Incontinence.

*1 time nocturia, ${ }^{* * 2}$ times nocturia, ${ }^{* * * 3}$ or more times nocturia.

8 patients that reported moderate symptoms, 4 had PVR $>100 \mathrm{~mL}$ versus 20 patients with PVR who reported no or mild symptoms based on IPSS. No correlation was found between IPSS symptom score and persistence of PVR, $p=0.32$. None of the patients in both groups reported severe symptoms. Table 3 shows the results of the individual IPSS questions. We also compared patients with and without treatment for PUV in combination with BNI. Patients with BNI and PUV scored median IPSS of 2.5, while patients with BNI and without PUV scored a median IPSS of 5, $p=0.03$.

\section{International Consultation on Incontinence Modular Questionnaire-Urinary Incontinence}

The median ICIQ-UI score was 1 (IQR 0-2.5) with an ICIQ-UI bother score of 0 (IQR 0-1). ICIQ-UI scores correlated with the 
TABLE 4 | Uroflowmetry results.

\begin{tabular}{llrc}
\hline Uroflowmetry & No. respondents (\%) & Median & (IQR) \\
\hline Total respondents & $40(100)$ & & \\
Voiding time (s) & $28(70)$ & 25.5 & $(17.3-35.5)$ \\
Flow time (s) & $28(70)$ & 26 & $(16.3-38.3)$ \\
Time to peak (s) & $28(70)$ & 9 & $(6-11)$ \\
Qmax $(\mathrm{mL} / \mathrm{s})$ & $28(70)$ & 30.1 & $(24.4-42.6)$ \\
Average flow rate $(\mathrm{mL} / \mathrm{s})$ & $28(70)$ & 17.4 & $(11.6-21.8)$ \\
Total voided volume $(\mathrm{mL})$ & $28(70)$ & 467.5 & $(285.3-582.3)$ \\
PVR $(\mathrm{mL})$ & $28(70)$ & 57.5 & $(23.8-100)$ \\
\hline
\end{tabular}

$I Q R$, interquartile range; No., number; $P V R$, post-void residual; $Q_{\max }$ maximum flow rate

bother scores with a coefficient of $0.72(p<0.0001)$. Patients without PUV reported to have more often mild UI (85\%) than patients also treated for PUV (34\%), $p=0.01$. The two patients who reported moderate symptoms also had a PVR $>100 \mathrm{~mL}$. None of the patients reported stress or nocturnal incontinence. Table 3 shows the results of the individual ICIQ-UI questions.

\section{Uroflowmetry}

Table 4 presents the uroflowmetry results. A bell shaped pattern was seen in $21(75 \%)$ of patients, staccato pattern in $6(21 \%)$, and a plateau-shaped pattern was seen in 1 patient (3.6\%). One uroflowmetry result $(3.6 \%)$ was under the 5 th percentile of the Pernkopf nomogram, and five (17.9\%) were above the 95th percentile. Figure 4 presents the Pernkopf nomogram.

\section{Further Follow-up}

Five patients were advised to revisit the outpatient clinic based on complaints or uroflowmetry results. Three patients showed up for further analysis. The first patient had a high voided volume (945 mL) and large PVR $(230 \mathrm{~mL})$ with a normal flow pattern; timed voiding was advised. The second patient had a staccato flow pattern with a significant PVR; he started with clean intermittent catheterization. The third had six UTIs in the past year; a normal flow pattern, normal kidneys on ultrasound, and normal cystoscopy results were found. No urethral strictures or upper tract changes were found.

\section{DISCUSSION}

In this study, we investigate long-term preservation of antegrade ejaculation after BNI in boys. Nearly 20 years after surgery, all of the 40 men experienced antegrade ejaculation, while 4 men had the impression of reduced ejaculatory volume. In this study we did not perform sperm analysis; this would have been useful to quantify our results. We chose not to include sperm analysis because we were afraid that this young adult group of men would refrain from participating. Prevalence of retrograde ejaculation in the general adolescent population is unknown. In patients attending fertility clinics, the prevalence ranges from 0.3 to $2 \%$ (16). In other studies investigating retrograde ejaculation after unilateral BNI in adult patients, prevalence ranges from 0 to $16 \%(17,18)$. In a study performed by Taskinen et al. investigating sexual function after PUVI (regardless of $\mathrm{BNI}$ ), similar prevalence of erectile dysfunction and similar
BOX 1 | Questionnaires.

\begin{tabular}{|c|c|}
\hline ICS male sex questions & ICS male sex bother questions \\
\hline 1a. Do you have an ejaculation of semen? & $\begin{array}{l}\text { b. How much of a problem is that } \\
\text { for you? }\end{array}$ \\
\hline \multicolumn{2}{|l|}{$\begin{array}{l}\text { Score: } 0=\text { yes, normal, } 1=\text { yes, reduced, } \\
2=\text { yes, strongly reduced, } 3=\text { not anymore, } \\
4=\text { never had }\end{array}$} \\
\hline \multicolumn{2}{|l|}{$\begin{array}{l}\text { 2a. Do you have pain or discomfort during } \\
\text { ejaculation? }\end{array}$} \\
\hline $\begin{array}{l}\text { Score: } 0=\text { no, } 1 \text { =yes, a little pain/ } \\
\text { discomfort, } 2=\text { yes, rather pain/discomfort, } \\
3=\text { yes, severe pain/discomfort, } 4=\text { not } \\
\text { applicable }\end{array}$ & $\begin{array}{l}\text { Score: } 0=\text { no problem, } 1=a \\
\text { little problem, } 2=\text { a serious } \\
\text { problem, } 3=\text { a major problem }\end{array}$ \\
\hline ICIQ-UI questions & ICIQ-UI bother questions \\
\hline $\begin{array}{l}\text { 1a. Do you have a sudden need to rush to } \\
\text { the toilet to urinate? }\end{array}$ & b. How much are you bothered? \\
\hline \multicolumn{2}{|l|}{$\begin{array}{l}\text { 2a. Does urine leak before you can get to } \\
\text { the toilet? }\end{array}$} \\
\hline \multicolumn{2}{|l|}{$\begin{array}{l}\text { 3a. Does urine leak when you cough or } \\
\text { sneeze? }\end{array}$} \\
\hline \multicolumn{2}{|l|}{$\begin{array}{l}\text { 4a. Do you ever leak for no obvious reason } \\
\text { and without feeling that you want to go? }\end{array}$} \\
\hline \multicolumn{2}{|l|}{ 5a. Do you leak urine when you are asleep? } \\
\hline \multicolumn{2}{|l|}{$\begin{array}{l}\text { 6a. How often have you had a slight wetting } \\
\text { of your pants a few minutes after you } \\
\text { had finished urinating and had dressed } \\
\text { yourself? }\end{array}$} \\
\hline $\begin{array}{l}\text { Score: } 0=\text { never, } 1=\text { occasionally, } \\
2=\text { sometimes, } 3=\text { most of the time, } 4=\text { all } \\
\text { of the time }\end{array}$ & $\begin{array}{l}\text { Score: } 0=\text { not at all, } 1=\text { slightly, } \\
2=\text { moderately, } 3=\text { greatly }\end{array}$ \\
\hline Total score: $0-24$ & Total score: $0-18$ \\
\hline
\end{tabular}

paternity rates are reported compared to men without PUVI. Erectile function and paternity rates were satisfactory in spite of chronic renal failure (19). In a study by Kajbafzadeh et al., no retrograde ejaculation was found after BNI at young age and no reduced sperm volume with normal sperm count in one out of six patients (20). Keihani et al. found similar results in 18 young adult men after concurrent treatment of PUV and BNI (21). The fact that a unilateral superficial BNI was done, only incising the obstructive ring, and thereby avoiding damage to the internal sphincter may contribute to the absence of retrograde ejaculation.

The goal of BNI is to achieve bladder outlet desobstruction in case of persistent BNO after PUVI or in case of severe primary $\mathrm{BNO}$. The beneficial effect of BNI is difficult to determine, because no controlled studies exist. In one semi-randomized study (type of procedure selected by the parents) unilateral BNI seemed urodynamically favorable over PUVI alone (20).

We found on the long term at adult age that $13.5 \%$ of patients had no LUTS, $64.9 \%$ had mild symptoms, and $21.6 \%$ had moderate symptoms. An earlier study in 151 healthy male medical students of the same age as our population revealed moderate LUTS in 7\% (22). In a long-term follow-up study using the IPSS in patients who underwent PUVI before age 3 years, LUTS were found in $7 / 24$ children (29.1\%) (23). In another longterm follow-up study in young adults treated for mild urethral 


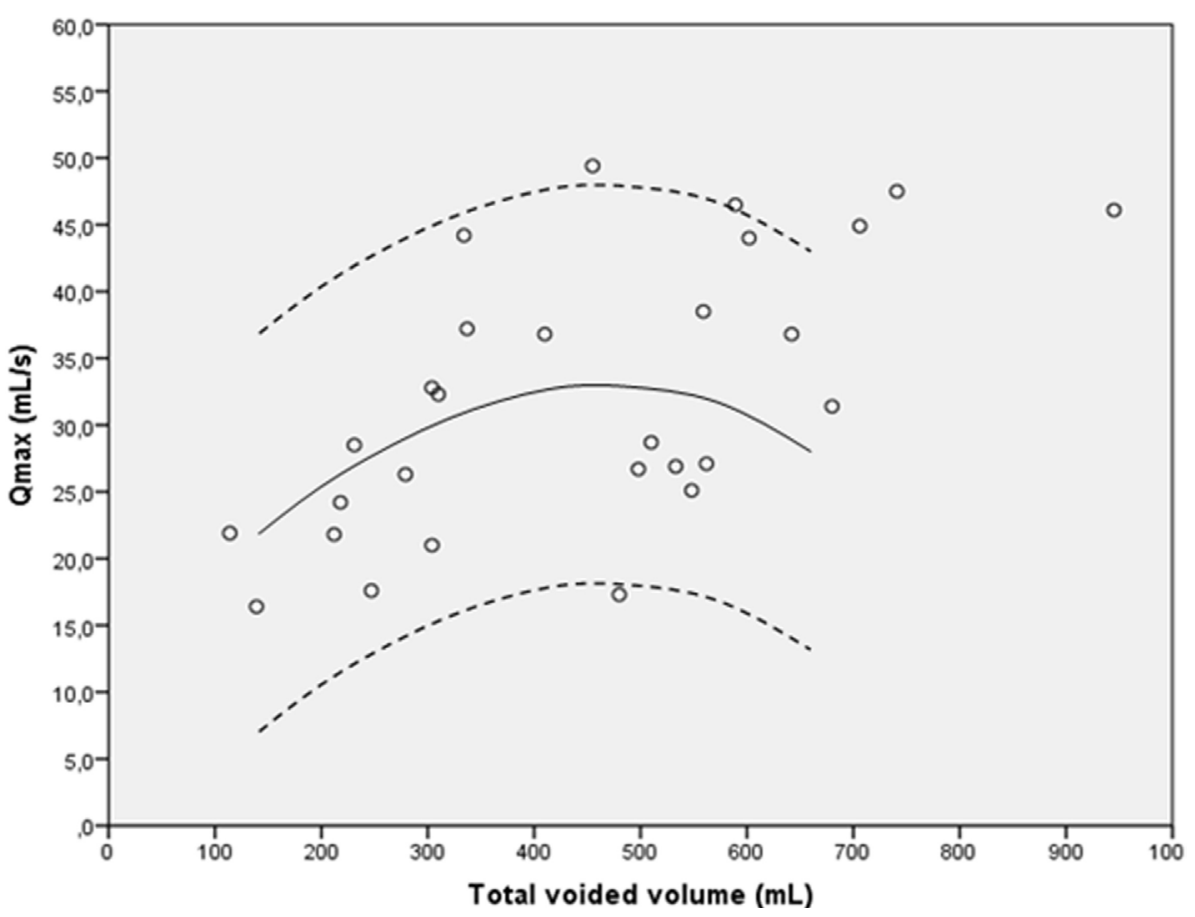

FIGURE 4 | Pernkopf nomogram for bladder neck incision $\leq 18$ years $(n=28)$. The solid line is the 50th percentile, and the dotted lines represent the 5th and 95th percentile.

obstruction in childhood, few micturition symptoms were found, not different from a reference group (24). When comparing our results with a multinational population-based (EPIC) survey in men aged $18-30$ years $(n=1,370)$, especially the symptom frequency was more prevalent in our study population (27 versus $4 \%$ ) (25). Unfortunately, the definition of presence or absence of symptoms was unclear in the EPIC study. Tikkinen et al. compared LUTS in men (age 18-57 years) who had PUVI during childhood to the general population (26). They found a twofold increase in prevalence of most LUTS in those with PUVI.

In the present study, two patients $(5.4 \%)$ reported moderate UI; this is higher than the prevalence found in the EPIC study $(2.4 \%)$ and in a national survey in the USA in men aged $20-34$ years $(0.7 \%)(25,27)$. However, in the latter study a different questionnaire than ICIQ-UI was used. Tikkinen et al. found a threefold higher prevalence of urgency incontinence and stress incontinence in patients treated with PUVI compared to the general population (26). In a previous long-term follow-up study, urgency incontinence and post-micturition incontinence were reported in 2.4 and $8.5 \%$ of men treated for mild PUV in childhood (24).

Besides showing results for the group as a whole, we also showed results for boys treated for BNI, PUV, and sometimes other urethral obstruction versus boys treated for BNI, sometimes with other urethral obstruction but without PUV. The patients not treated for PUV reported significant higher IPSS and ICIQ-UI scores, although scores were still in mild complaints rates. BNO without PUV may have another cause than secondary
BNO due to PUV. In patients with PUV, the BNO is thought to be a result of detrusor hypertrophy caused by obstruction. The different cause of primary BNO may be responsible for other long-term outcomes.

We did not find significant changes between the two groups, but both groups were small. Furthermore, as in both groups in a large part of the patients also other urethral obstructions were present, we cannot conclude that the presence of PUV influences outcome based on this study.

Uroflowmetry results were in the normal range and very similar to the mean values of healthy male students of the same age (22). Similar results were found in a previous study in men after PUVI as a child (23). A plateau-shaped curve (possibly indicative of urethral stricturing) was seen in one patient (3.6\%). However, in healthy male students a plateau-shaped curve was found in 5\% (23). In our patients with abnormal flow pattern, urethral stricture could not be confirmed. No clear explanation can be found for these anomalous uroflowmetry results. As only single measurements were done, repeated uroflowmetry might have revealed other results.

Overall, long-term effect on micturition in men with childhood desobstruction with or without BNI as a child has been studied relatively well. Regarding LUTS, outcomes vary widely, varying between no difference to twice as much symptoms as in the general population, with irritative LUTS being most prominent. Incontinence seems more prevalent than in the general population, and uroflowmetry is not clearly different from controls. However, the question whether additional or primary 
SBNI is beneficial and recommendable is still unclear and has to be determined in a large randomized study.

A limitation of the present study is the relatively low response rate $(37.7 \%)$; outdated contact details made it difficult to contact selected patients. Also, among the contacted patients, some refused to participate and some did not respond. The reason for refusal varied from: no time, no complaints, or unpleasant associations with hospitals. This may have resulted in some selection bias in the way that there might be an overrepresentation of patients with complaints. The response rate compares with a large meta-analysis by Shih and Fan showing an average response rate for young adults of $45 \%$ for mail surveys and a response rate of $60 \%$ of traceable patients as found by Larcombe et al. $(28,29)$.

Other shortcomings are the lack of randomization in determining whether or not SBNI was done, and the fact that for primary SBNI assessment of the bladder neck was done subjectively by the pediatric urologist. In cases of secondary SBNI, this was performed after urodynamic proof of persistent infravesical obstruction after earlier urethral desobstruction. The questionnaires used were validated, whereas the additional questions were not. Because ejaculation volume is difficult to objectify, interpretation of the reported data should be done with caution. A limitation of the ICIQ-UI is that the amount of urine loss is not obtained; it questions whether there is leakage but does not distinguish between urine droplets and large volumes. We did not do repeated cystoscopy as a routine, because in pediatric patients general anesthesia is needed. In

\section{REFERENCES}

1. Marion G. Surgery of the neck of the bladder. Br J Urol (1933) 5(4):351-80. doi:10.1111/j.1464-410X.1933.tb06833.x

2. Androulakakis PA, Karamanolakis DK, Tsahouridis G, Stefanidis AA, Palaeodimos I. Myogenic bladder decompensation in boys with a history of posterior urethral valves is caused by secondary bladder neck obstruction? BJU Int (2005) 96(1):140-3. doi:10.1111/j.1464-410X.2005.05583.x

3. Casale AJ. Posterior urethral valves. 10th ed. In: Wein AJ, Kavoussi LR, Partin A, Peters C, editors. Campbell-Walsh Urology. (Vol. 4), Philadelphia: Elsevier Saunders (2012). p. 3589-610.

4. Bauer SB, Dieppa RA, Labib KK, Retik AB. The bladder in boys with posterior urethral valves: a urodynamic assessment. J Urol (1979) 121(6): 769-73.

5. Grafstein NH, Combs AJ, Glassberg KI. Primary bladder neck dysfunction: an overlooked entity in children. Curr Urol Rep (2005) 6(2):133-9. doi:10.1007/ s11934-005-0082-6

6. Avni EF, Schulman CC. The origin of vesico-ureteric reflux in male newborns: further evidence in favour of a transient fetal urethral obstruction. Br J Urol (1996) 78(3):454-9. doi:10.1046/j.1464-410X.1996.00106.x

7. Kumar A, Banerjee GK, Goel MC, Mishra VK, Kapoor R, Bhandari M. Functional bladder neck obstruction: a rare cause of renal failure. J Urol (1995) 154(1):186-9. doi:10.1016/S0022-5347(01)67262-8

8. Turner-Warwick R, Whiteside CG, Worth PHL, Milroy EJG, Bates CP. A urodynamic view of the clinical problems associated with bladder neck dysfunction and its treatment by endoscopic incision and trans-trigonal posterior prostatectomy. $\mathrm{Br} J$ Urol (1973) 45(1):44-59. doi:10.1111/j. 1464-410X.1973.tb00044.x

9. Yang Q, Peters TJ, Donovan JL, Wilt TJ, Abrams P. Transurethral incision compared with transurethral resection of the prostate for bladder outlet obstruction: a systematic review and meta-analysis of randomized controlled trials. JUrol (2001) 165(5):1526-32. doi:10.1016/S0022-5347(05) 66342-2 selected cases who had cystoscopy after SBNI, a normal appearance of the bladder neck was seen.

\section{CONCLUSION}

Bladder neck incision is sometimes indicated and can be done safely. There seems no negative long-term effect on antegrade ejaculation and incontinence.

\section{ETHICS STATEMENT}

This study was carried out in accordance with the recommendations of the medical ethic committee of University Medical Center Utrecht with written informed consent from all subjects. All subjects gave written informed consent in accordance with the declaration of Helsinki.

\section{AUTHOR CONTRIBUTIONS}

$\mathrm{EH}$ contributed to the collection of patient information and follow-up data, processing data, and writing the manuscript. $\mathrm{PH}$ contributed to data collection, assisted with interpreting results as well as writing and changes to the manuscript. JK worked on the collection of patient information and follow-up data and contributed to manuscript. TJ and LK contributed to study outline and writing the manuscript.

10. Kochakarn W, Lertsithichai P. Unilateral incision for primary bladder neck obstruction: symptom relief and fertility preservation. World J Urol (2003) 21(3):159-62. doi:10.1007/s00345-003-0343-2

11. Abdel-Basir Sayed M. Bladder neck resection with preservation of antegrade ejaculation: Basir technique. J Endourol (2003) 17(2):109-11. doi:10.1089/ 08927790360587441

12. Barry MJ, Fowler FJ Jr, O'Leary MP, Bruskewitz RC, Holtgrewe HL, Mebust WK, et al. The American Urological Association symptom index for benign prostatic hyperplasia. The measurement committee of the American Urological Association. J Urol (1992) 148(5):1549-57.

13. Avery K, Donovan J, Peters TJ, Shaw C, Gotoh M, Abrams P. ICIQ: a brief and robust measure for evaluating the symptoms and impact of urinary incontinence. Neurourol Urodyn (2004) 23(4):322-30. doi:10.1002/nau.20041

14. Abrams P, Avery K, Gardener N, Donovan J; ICIQ Advisory Board. The international consultation on incontinence modular questionnaire: www. iciq.net. J Urol (2006) 175(3 Pt 1):1063-6. doi:10.1016/S0022-5347(05) 00348-4

15. Pernkopf D, Plas E, Lang T, Daha K, Kubin K, Treu T, et al. Uroflow nomogram for male adolescents. J Urol (2005) 174(4 Pt 1):1436-9; discussion 1439. doi:10.1097/01.ju.0000173694.86127.ae

16. Jannini EA, Lenzi A. Ejaculatory disorders: epidemiology and current approaches to definition, classification and subtyping. World J Urol (2005) 23(2):68-75. doi:10.1007/s00345-004-0486-9

17. Kaplan SA, Te AE, Jacobs BZ. Urodynamic evidence of vesical neck obstruction in men with misdiagnosed chronic nonbacterial prostatitis and the therapeutic role of endoscopic incision of the bladder neck. J Urol (1994) 152(6 Pt 1):2063-5.

18. Moisey CU, Stephenson TP, Evans C. A subjective and urodynamic assessment of unilateral bladder neck incision for bladder neck obstruction. Br J Urol (1982) 54(2):114-7. doi:10.1111/j.1464-410X.1982.tb13531.x

19. Taskinen S, Heikkilä J, Santtila P, Rintala R. Posterior urethral valves and adult sexual function. BJU Int (2012) 110(8 Pt B):E392-6. doi:10.1111/j. 1464-410X.2012.11091.X 
20. Kajbafzadeh AM, Payabvash S, Karimian G. The effect of bladder neck incision on urodynamic abnormalities of children with posterior urethral valves. J Urol (2007) 178(5):2142-7. doi:10.1016/j.juro.2007.07.046

21. Keihani S, Kajbafzadeh AM, Kameli SM, Abbasioun R. Long-term impacts of concurrent posterior valve ablation and bladder neck incision on urinary incontinence and ejaculation. Urology (2017) 99:278-80. doi:10.1016/j. urology.2016.09.036

22. Rynja SP, Wouters GA, van Schaijk M, Kok ET, De Jong TP, De Kort LM. Long-term followup of hypospadias: functional and cosmetic results. J Urol (2009) 182(4 Suppl):1736-43. doi:10.1016/j.juro.2009.03.073

23. Caione P, Nappo SG. Posterior urethral valves: long-term outcome. Pediatr Surg Int (2011) 27(10):1027-35. doi:10.1007/s00383-011-2946-9

24. Kieft JH, Hennus PM, Hoenjet E, Rynja SP, De Jong TP, Bosch JL, et al. Long-term follow-up after transurethral treatment of infravesical obstruction in boys. Urology (2014) 83(5):1155-60. doi:10.1016/j.urology.2013. 11.038

25. Irwin DE, Milsom I, Kopp Z, Abrams P, Artibani W, Herschorn S. Prevalence, severity, and symptom bother of lower urinary tract symptoms among men in the EPIC study: impact of overactive bladder. Eur Urol (2009) 56(1):14-20. doi:10.1016/j.eururo.2009.02.026

26. Tikkinen KAO, Heikkilä J, Rintala RJ, Tammela TLJ, Taskinen S. Lower urinary tract symptoms in adults treated for posterior urethral valves in childhood: matched cohort study. J Urol (2011) 186(2):660-6. doi:10.1016/j. juro.2011.03.150

27. Markland AD, Goode PS, Redden DT, Borrud LG, Burgio KL. Prevalence of urinary incontinence in men: results from the national health and nutrition examination survey. J Urol (2010) 184(3):1022-7. doi:10.1016/j. juro.2010.05.025

28. Shih TH, Fan X. Comparing response rates from web and mail surveys: a meta-analysis. Field methods (2008) 20:249-227. doi:10.1177/15258 22X08317085

29. Larcombe I, Mott M, Hunt L. Lifestyle behaviours of young adult survivors of childhood cancer. Br J Cancer (2002) 87:1204-9. doi:10.1038/sj.bjc.6600632

Conflict of Interest Statement: None of the authors has any conflict of interest to report. No external funding has been used for this study. The study has been approved by the local ethical committee.

Copyright (C) 2017 Hennus, Hoenjet, Kieft, de Jong and de Kort. This is an open-access article distributed under the terms of the Creative Commons Attribution License (CC BY). The use, distribution or reproduction in other forums is permitted, provided the original author (s) or licensor are credited and that the original publication in this journal is cited, in accordance with accepted academic practice. No use, distribution or reproduction is permitted which does not comply with these terms. 